\title{
Concentrations and characteristics of amphibole fibres in the lungs of workers exposed to crocidolite in the British gas-mask factories, and elsewhere, during the second world war
}

\author{
A MORGAN AND A HOLMES \\ From the Environmental and Medical Sciences Division, Atomic Energy Research Establishment, Harwell, \\ Oxfordshire OXI1 ORA, UK
}

ABSTRACT Concentrations and length distributions of uncoated and coated amphibole fibres in the lungs of 27 workers at the Leyland, Nottingham, and Blackburn gas-mask factories were measured after death with the light microscope using the membrane filter technique. Measurements were also made on a worker exposed to crocidolite at the Chemical Defence Experimental Establishment, Porton, and on three miners from the Wittenoom mine in Western Australia where the crocidolite used in the manufacture of military respirators is reputed to have originated. In selected cases, fibre concentrations and dimensions were also measured with the electron microscope. All but two subjects died with a mesothelial tumour. Fibre concentrations ranged from $7 \times 10^{4}$ to almost $10^{9}$ fibres/g dry weight. There appeared to be no relation between latent period and fibre concentration. The significance of the wide range of fibre concentrations which was associated with the development of mesothelial tumours is discussed and also the relation between the relative frequency and dimensions of uncoated and coated fibres.

A relatively high incidence of asbestos-related diseases has been reported ${ }^{1}$ among workers employed at gas-mask factories in the United Kingdom during the second world war. Two types of respirator were manufactured during this period to specifications developed at the Chemical Defence Experimental Establishment (CDEE), Porton. The "civilian" respirator contained a filter that incorporated chrysotile asbestos and the "military" a filter that incorporated crocidolite. It was thought that most of the crocidolite used in the military respirators originated from the Wittenoom mine in Western Australia, where asbestos production started in 1938: recent evidence, however, suggests that some may have come from South Africa. Filter pads for the military respirators were produced at factories in Barking, Essex, and Hebden Bridge, Yorkshire, and were incorporated into respirators at factories in Nottingham, Leyland (near Preston), and

Received 13 February 1981

Accepted 28 Mạch 1981
Birmingham. It is known that the number of workers employed at Birmingham was small. Both civilian and military respirators were assembled at Blackburn, Lancashire, where there were three factories.

In the present study the concentrations and characteristics of uncoated and coated amphibole asbestos fibres were measured in lung tissue obtained after death from some of the workers at the Leyland, Nottingham, and Blackburn factories, all but one of whom had died with mesothelial tumours. Similar measurements were made on a worker at CDEE, Porton, who had been exposed to crocidolite and died with a mesothelial tumour. Measurements on three workers at the Wittenoom mine are also included, two of whom died with mesothelial tumours.

The detection of fibres was carried out using the membrane filter technique and phase contrast microscopy. ${ }^{2}$ This enables fibres with diameters down to about $0.2 \mu \mathrm{m}$ to be detected so that only about $10-15 \%$ of the crocidolite fibres present are resolved. No information on chrysotile exposure was 
obtained.

\section{Materials and methods}

Most of the samples of lung tissue were provided by pathologists at hospitals in Liverpool, Nottingham, and Preston. Generally, a single block of formalinfixed material, taken from the base of one lower lobe, was provided, but in some instances several blocks from both upper and lower lobes were supplied. Details of the cases from which lung tissue was obtained are given in table 1 which includes age at death, cause of death, estimated latent period between first exposure and death from mesothelial tumours, and, where available, information on the duration of occupational exposure to crocidolite.

ANALYSIS OF LUNG TISSUE

About $0.5 \mathrm{~g}$ of tissue was weighed accurately and digested with sodium hypochlorite (domestic bleach) as described by Morgan and Holmes. ${ }^{2}$ An adjacent block, about $1 \mathrm{~g}$ in weight, was dried to constant weight at $110^{\circ} \mathrm{C}$ to obtain the wet/dry ratio. After digestion was complete, lipids were extracted with diethyl ether and an aliquot of the resulting suspension filtered through a $2.5 \mathrm{~cm}$ diam Millipore GS membrane filter (pore size $0 \cdot 22 \mu \mathrm{m}$ ). The filter was washed well with water and allowed to dry. Half the filter was placed on a microscope slide and cleared with a dimethylformamide/acetic acid/water

Table 1 Details of subjects from whom lung tissue was obtained at necropsy

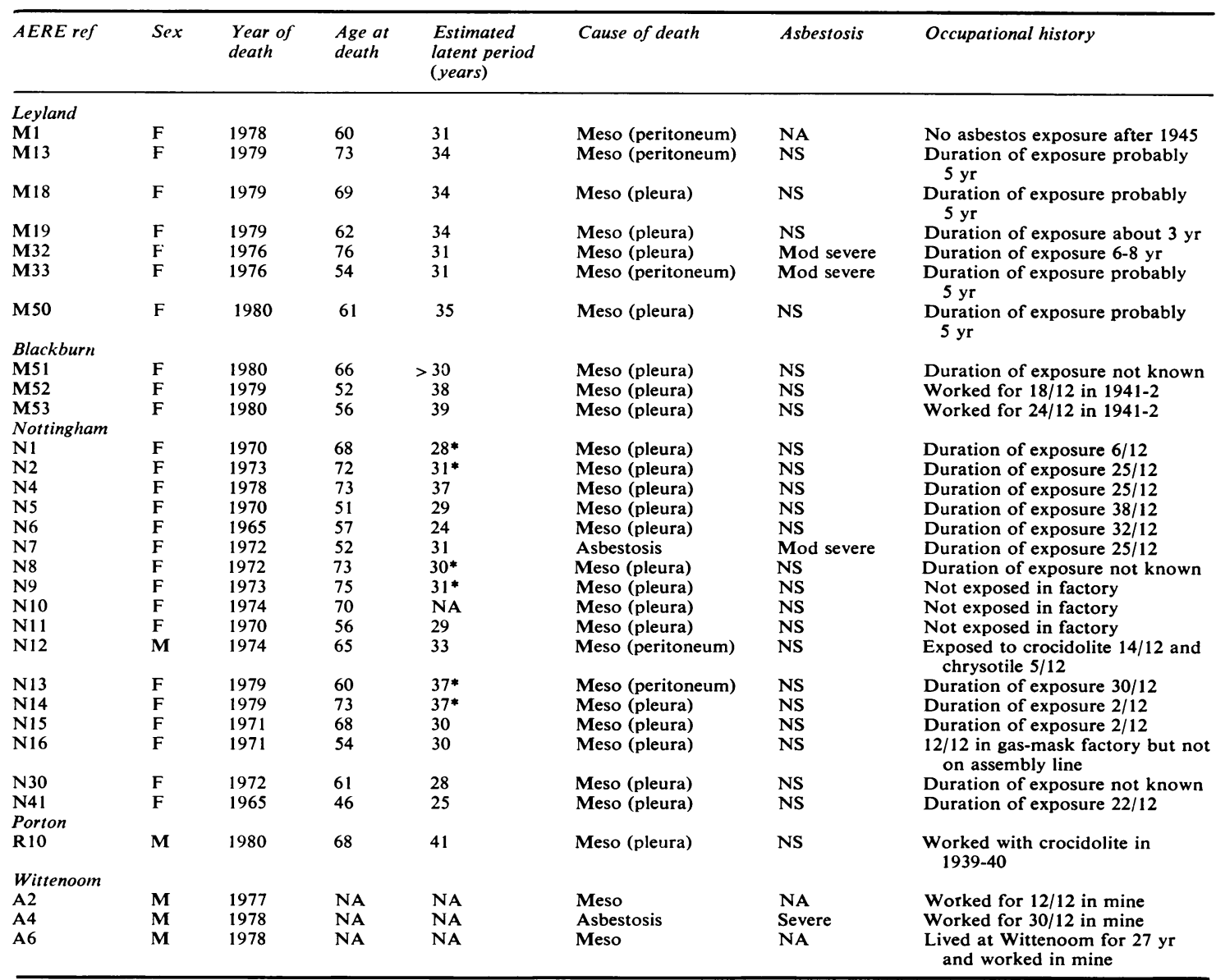

NA $=$ Not available

NS $=$ Not significant.

* Latent period assumed to start in 1942. 
mixture (JMM Le Guen, personal communication). The other half was retained for examination with the electron microscope. If the concentration of fibres, or of non-fibrous dust, was too great to prevent the accurate detection and sizing of fibres, additional filters were prepared from smaller volumes of the suspension

Uncoated rectilinear fibres greater than about $2.5 \mu \mathrm{m}$ in length were counted and sized, using phase contrast and a Porton-type eyepiece graticule, at a magnification of about $\times 640$ (Zeiss Photomicroscope III). Coated fibres were counted and sized at a magnification of $\times 256$ although a higher magnification was used in doubtful cases. All fibres with any evidence of coating were classified as "coated" even though they may have been uncoated for the greater part of their length. Whenever possible, the lengths of at least 200 uncoated and of 100 coated fibres were measured and classified in the following categories: $2 \cdot 5-4 \cdot 9,5-9 \cdot 9,10-19 \cdot 9,20-39 \cdot 9,40-79 \cdot 9$ and $>80 \mu \mathrm{m}$. Fibre concentrations were expressed in units of $10^{6}$ fibres/g dry weight of lung.

\section{Results}

Concentrations of fibres (uncoated, coated, and total) in lung tissue, measured with the light microscope, are given in table 2. Total concentrations ranged from 0.07 to $860 \times 10^{6} / \mathrm{g}$ dry weight. Included in table 2 , in parentheses, are the percentages of the optically visible fibres which were coated. These values ranged from 1 to $24 \%$.

The consistent "thinness" of the fibres extracted from the lungs of the gas-mask factory workers exposed to crocidolite is very characteristic, a high proportion being only just resolved with the optical microscope. Subjectively, the diameter distribution is clearly quite different from, for example, that encountered in many shipyard workers who have been exposed to intrinsically thicker amphibole fibres. Various workers ${ }^{2-4}$ have pointed out that the lengths of asbestos fibres extracted from human lung are distributed log-normally. This applied to the lengths of both uncoated and coated fibres measured with the optical microscope in the present study. The count median lengths (CMLs) of both

Table 2 Concentrations and count median lengths of uncoated and coated fibres in lung tissue

\begin{tabular}{|c|c|c|c|c|c|}
\hline \multirow[t]{2}{*}{ AERE ref } & \multicolumn{3}{|c|}{ Fibre concentration $\left(10^{\circ} / \mathrm{g}\right.$ dry weight) } & \multicolumn{2}{|c|}{ Count median length $(\mu \mathrm{m})$} \\
\hline & Uncoated & Coated (\%) & Total & Uncoated & Coated \\
\hline \multicolumn{6}{|l|}{ Leyland } \\
\hline Mi & 13 & $0.34(3)$ & $13 \cdot 3$ & 14 & 36 \\
\hline M13 & $6 \cdot 8$ & $1 \cdot 2(15)$ & 8.0 & 12 & 23 \\
\hline M18 & $6 \cdot 8$ & $0.52(7)$ & $7 \cdot 4$ & 14 & 22 \\
\hline M19 & 0.4 & $0.03(7)$ & 0.4 & 14 & ND \\
\hline M32 & 169 & $47 \quad(22)$ & 216 & 9 & 19 \\
\hline M33 & 127 & $16 \quad$ (11) & 143 & 10 & 23 \\
\hline M50 & 0.7 & $0 \cdot 10(12)$ & $0 \cdot 8$ & 11 & ND \\
\hline $\begin{array}{l}\text { Blackburn } \\
\text { M51 }\end{array}$ & $4 \cdot 0$ & $0.53(12)$ & $4 \cdot 6$ & 13 & 31 \\
\hline M52 & 0.4 & $0.07(16)$ & 0.5 & ND & ND \\
\hline M53 & $6 \cdot 5$ & $0.36(5)$ & 6.9 & 14 & 27 \\
\hline \multicolumn{6}{|l|}{ Nottingham } \\
\hline N1 & 90 & $17 \quad(16)$ & 107 & 10 & 23 \\
\hline N2 & $4 \cdot 5$ & $0.27(6)$ & 4.8 & 13 & 23 \\
\hline N4 & $1 \cdot 3$ & $0 \cdot 22(15)$ & 1.5 & 13 & 28 \\
\hline N5 & 124 & $3 \cdot 3(3)$ & 127 & 11 & 33 \\
\hline N6 & $1 \cdot 3$ & $0.03(2)$ & 1.4 & 13 & 29 \\
\hline N7 & 25 & $5 \cdot 5(18)$ & 30 & 13 & 26 \\
\hline N8 & $0 \cdot 1$ & $<0.01(5)$ & $0 \cdot 1$ & ND & ND \\
\hline N9 & $1 \cdot 2$ & $0 \cdot 14(11)$ & $1 \cdot 3$ & ND & ND \\
\hline N10 & $2 \cdot 4$ & $0.42(15)$ & 2.8 & 15 & 27 \\
\hline N11 & $0 \cdot 4$ & $0.05(11)$ & 0.5 & ND & ND \\
\hline N12 & 21 & $5.5(21)$ & 27 & 12 & 24 \\
\hline N13 & 40 & 5.2 (11) & 46 & 15 & 26 \\
\hline N14 & 0.5 & $0.04(8)$ & 0.5 & ND & 30 \\
\hline N15 & $7 \cdot 1$ & $0.89(11)$ & 8.0 & 14 & 23 \\
\hline N16 & 0.6 & $0 \cdot 18(24)$ & 0.8 & 14 & 28 \\
\hline N30 & $1 \cdot 4$ & $0.05(3)$ & 1.5 & 10 & ND \\
\hline N41 & 35 & $2 \cdot 3(6)$ & 37 & 10 & 30 \\
\hline \multicolumn{6}{|l|}{ Porton } \\
\hline R10 & $2 \cdot 2$ & $0 \cdot 18(8)$ & $2 \cdot 4$ & 12 & 32 \\
\hline \multicolumn{6}{|l|}{ Wittenoom } \\
\hline $\begin{array}{l}\text { A2 } \\
\text { A4 }\end{array}$ & $7 \cdot 8$ & $0.54(7)$ & $8 \cdot 3$ & 10 & 23 \\
\hline $\begin{array}{l}\text { A4 } \\
\text { A6 }\end{array}$ & 850 & 13 (1) & 863 & 3 & 20 \\
\hline A6 & 760 & $9 \cdot 5$ (1) & 770 & 3 & 27 \\
\hline
\end{tabular}

ND $=$ Not determined. 
types of fibre are included in table 2 in cases where a minimum of 100 were measured. The mean values of the CMLs of uncoated fibres for the Leyland and Nottingham gas-mask factory workers were 12 and $12.5 \mu \mathrm{m}$ respectively. Corresponding mean values for coated fibres were 24.6 and $26.9 \mu \mathrm{m}$. Differences between the mean values were not significant in either case. The CMLs of uncoated and coated fibres for the Blackburn factory workers and for the Porton case fell within the same ranges. CMLs of uncoated fibres measured in the two Wittenoom miners with very high fibre concentrations, however, were much shorter (about $3 \mu \mathrm{m}$ ), and the reason for this is discussed below.

In three cases (M32, N5, and A6) filters were also examined with the electron microscope at a magnification of $\times 2240$ and photographs taken of random fields. The negatives were printed at a further magnification of $\times 2$ so that the fibres were counted and sized at an overall magnification of $\times \mathbf{4 4 8 0}$ (fig 1). Estimates of CMLs and count median diameters (CMDs) were made for these three subjects and are given in table 3 together with the geometric standard deviations $(\sigma \mathrm{g})$. The fibre densities (fibres $\mathrm{mm}^{-2}$ ) were also measured and compared with densities measured on corresponding filters by optical microscopy. The CMD for the crocidolite fibres in the miner's lung was $0.13 \mu \mathrm{m}$ and, in this case, there was evidence of a bimodal diameter distribution.

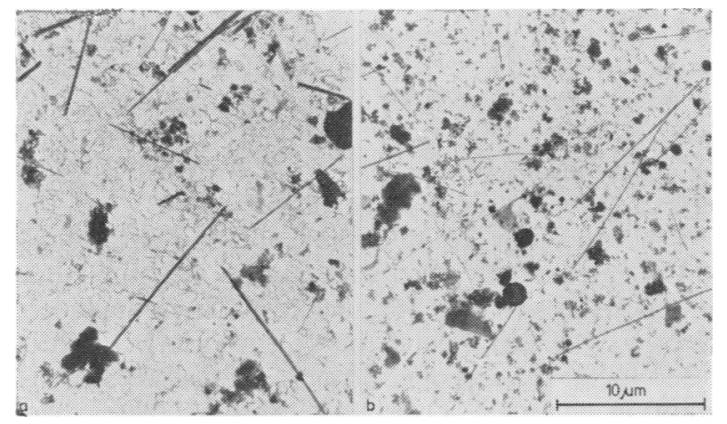

Fig 1 Electron micrographs of fibres isolated from (a) lungs of an Australian crocidolite miner (A6) and (b) lungs of a Nottingham gas-mask factory worker (N5). Note thicker fibres in former.
Fibres in the lungs of the gas-mask factory workers were thinner, presumably because they had been milled. It has been reported by Jones et al ${ }^{5}$ that the lungs of some of the Nottingham workers contain significant numbers of chrysotile in addition to crocidolite fibres, and inclusion of these will probably have the effect of reducing the CMD. Pooley6 reported a value of $0.14 \mu \mathrm{m}$ for the diameter of crocidolite fibres in human lung but Timbrell et al ${ }^{7}$ indicated that fibres of Australian crocidolite are very thin with an even higher proportion of fine fibres than crocidolite from Cape Province in South Africa.

Estimates of the proportion of fibres detected with the electron microscope which were also detected with the optical averaged $14 \%$, which approximates to the proportion of fibres with diameters exceeding $0.2 \mu \mathrm{m}$. Thus when considering the fibre concentrations reported in this paper it must be remembered that they should be multiplied by a factor of about 7 to give an estimate of the total number of crocidolite fibres present. As shown in table 3, the CMLs of fibres measured with the electron microscope were somewhat shorter than those obtained with the optical microscope due, no doubt, to the difficulty in detecting short thin fibres with the latter. Variations in CML between the three cases studied with the electron microscope, however, followed a pattern similar to that observed with the optical microscope.

\section{Discussion}

The gas-mask factory workers constitute a group that is probably unique because many of them were exposed occupationally to only a single type of fibre for a limited and relatively well-defined period. Thus for those who have died (and will die) with mesothelial tumours, latent periods can be determined with an accuracy that is not possible in most other occupationally exposed groups. Although there is insufficient information to reconstruct the integrated dose of airborne fibres to which individual workers were exposed, the inability of the lung to clear fibres exceeding a critical length ${ }^{2} 48$ means that the concentration of such fibres remaining in the

Table 3 Measurements of fibre dimensions with the electron and optical microscopes

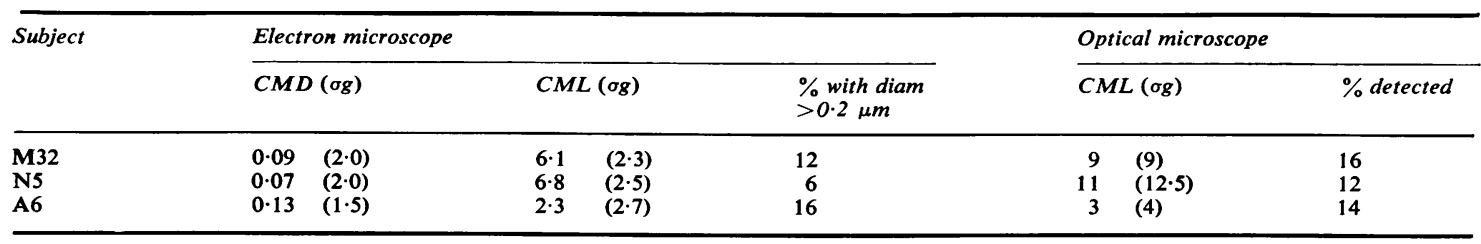


lung provides an accurate index of integrated exposure.

\section{FIBRE CONCENTRATIONS}

The concentrations of crocidolite fibres in the lungs of the gas-mask factory workers ranged from 0.07 to $2 \cdot 16 \times 10^{6} / \mathrm{g}$ dry weight. Among the Nottingham workers, the one with the longest recorded exposure (N5) had the greatest fibre concentration, but there was no clear correlation between concentration and duration of exposure for the remainder. Workers who were not employed on the assembly line still had significant fibre concentrations. The geometric mean fibre concentration for the Leyland workers $\left(8.6 \times 10^{6}\right)$ was about twice that for the Nottingham workers $\left(4.6 \times 10^{6} / \mathrm{g}\right.$ dry weight $)$. This is consistent with the report that only at the latter factory were effective precautions taken to control dust levels. On the other hand, it appears that the average duration of exposure may have been longer for the Leyland workers so that these figures cannot be used to draw conclusions regarding the relative magnitude of airborne dust levels. The presence in the lungs of the Blackburn factory workers of amphibole fibres, with dimensions similar to those encountered at the other factories, indicates that exposure to crocidolite occurred there also. The Porton worker was known to have been exposed to

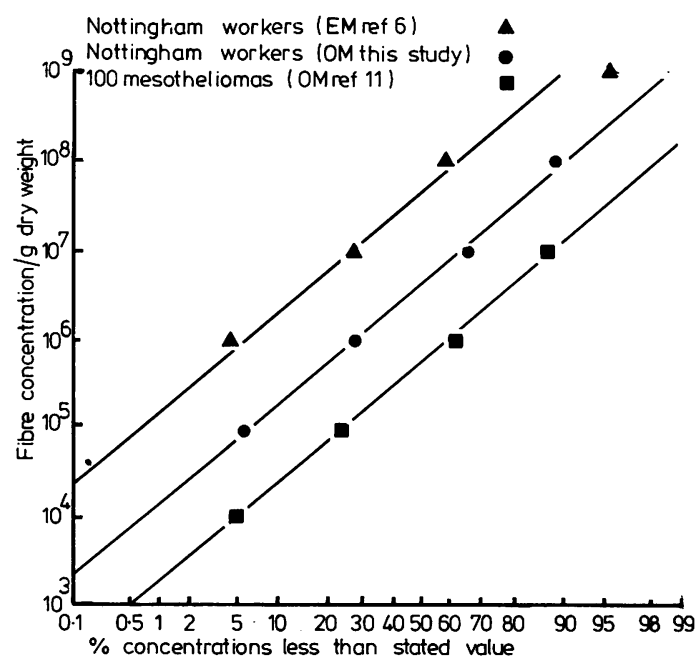

Fig 2 Distributions of fibre concentrations obtained from Nottingham gas-mask factory workers. Upper line represents results obtained by Jones et al ${ }^{\mathbf{6}}$ for Nottingham workers using electron microscope. Lower line represents concentrations found in 100 cases of mesothelioma reported by Whitwell et al. ${ }^{11}$ crocidolite.

Concentrations of crocidolite fibres in the lungs of two of the Wittenoom miners approached $10^{9} / \mathrm{g}$ dry weight. The observation that, in two cases, the duration of exposure was no longer than for many of the gas-mask factory workers suggests that dust levels were considerably greater than in the gas-mask factories. For miners at Wittenoom there was probably significant environmental, in addition to occupational, exposure due to the surfacing of roads with spoil containing crocidolite. The high concentrations observed are consistent with the high incidence of asbestosis reported among the Wittenoom miners by McNulty. ${ }^{9}$ As can be seen from table 1 only three of the gas-mask factory workers had asbestosis as a complicating factor. Reference to table 2 shows that they were among those with the highest fibre counts.

When the fibre concentrations in the lungs of the Nottingham gas-mask factory workers are plotted in log probability form they can be represented by a straight line (fig 2). This shows that the values are distributed log-normally with a median of about $4 \times 10^{6} / \mathrm{g}$ dry weight and a geometric standard deviation $(\sigma \mathrm{g})$ of about 12 . Jones et al,,$^{5}$ using the electron microscope, have also measured the concentrations of various types of asbestos in the lungs of 22 Nottingham gas-mask factory workers and found that crocidolite fibres predominated in most cases. The distribution of crocidolite fibre concentrations they observed is included in fig 2 and is also roughly log-normal with a median of $40 \times 10^{6} / \mathrm{g}$ dry weight. As would be expected, because of the greater resolution of the electron microscope, their line is displaced by almost an order of magnitude compared with the present series but the value of $\sigma \mathrm{g}$ is similar.

Concentrations of amphibole fibres in the lungs of 100 patients who died with pleural mesothelioma have been reported by Whitwell et al, ${ }^{10}$ who included fibres with length greater than $6 \mu \mathrm{m}$ measured with the optical microscope using a Fuchs-Rosenthal counting chamber. Over $90 \%$ of these cases had industrial exposure to asbestos in, for example, shipyards, asbestos factories, and insulation. That the concentrations of amphibole fibres in this series are also distributed log-normally is shown in fig 2. The median fibre concentration in Whitwell's series is $0.6 \times 10^{6} / \mathrm{g}$ dry weight, about seven times lower than the median for the Nottingham gas-mask factory workers. In an intercomparison between Whitwell's laboratory and our own, however, samples of lung tissue from 37 patients were analysed. As Whitwell measured only fibres exceeding $6 \mu \mathrm{m}$ in length a linear regression analysis was performed in which his results were compared with our own 
estimates of the concentration of fibres exceeding $5 \mu \mathrm{m}$. Although the results were well correlated $(r=0.92)$, we detected, on average, over five times as many fibres as Whitwell. This indicates that finer fibres can be detected with the membrane filter technique than with the counting chamber. Taking this factor into account and also the fact that Whitwell et al did not include fibres under $6 \mu \mathrm{m}$ in length in their assessments, it appears that the distribution of fibre concentrations in the Nottingham gas-mask factory workers and in Whitwell's series of 100 cases of mesothelioma are quite similar, with comparable median values.

It is worthwhile commenting on the factors that result in a log-normal distribution pattern of amphibole fibre concentrations in the lungs of the Nottingham gas-mask factory workers who died with mesothelioma and possibly in other occupationally exposed populations. The main factors which determine the shape of the curve are $(a)$ the dose-response relationship for mesothelioma induction and $(b)$ the distribution of dose in the population. It seems certain that people with high concentrations of crocidolite fibre in lung are at greater risk of dying with mesothelial tumours than those with low. For example, Jones et $a^{5}$ showed that, with the Nottingham workers, there is a positive correlation between duration of exposure and incidence of mesothelial tumours and Hobbs et al ${ }^{11}$ have reported a similar relationship for the Wittenoom miners. Sheers and Coles $^{12}$ also found evidence of a dose-response relationship for mesothelioma induction in workers at Devonport Dockyard, where the principal exposure appears to have been to crocidolite. We consider that, except at very high dose levels when clearance is impaired, the residual fibre concentration in lung provides the most accurate index of integrated exposure but such information can only be obtained after death. With regard to the distribution of dose, it seems likely that a few of the Nottingham workers may have been more heavily exposed than the majority by virtue either of their particular occupation or duration of employment in the factory. Workers, employed in the same factory but not fabricating gas-masks, appear to have been exposed to crocidolite to some degree. ${ }^{5}$ If it were possible to measure after death the fibre concentration in the lungs of all the Nottingham gas-mask factory workers, irrespective of cause of death, it should be possible to derive the dose-response relationship for the induction of mesothelial tumours by crocidolite asbestos. One complicating factor is that in heavily exposed subjects (certainly those with fibre concentrations exceeding $10^{8} / \mathrm{g}$ dry weight) there will be a competing risk of mortality from asbestosis.

Extrapolation of the lines in fig 2 indicates that there may be a small, but significant, risk of developing mesothelial tumours even when the concentration of crocidolite fibres in the lung is below the level normally considered to result from occupational exposure. In the study reported by Whitwell et al ${ }^{10}$ there was a considerable degree of overlap in amphibole fibre concentrations in the lungs of the control series and 100 cases of mesothelioma. This is to be expected if the probability of developing a mesothelioma at low fibre concentrations is small. In deciding whether mesothelial tumours are spontaneous, or caused by asbestos exposure, it is clearly important to have access to methods that permit the accurate determination of relatively low concentrations of amphibole fibres in the lung.

In this study, latent periods ranged from 24 to 39 years. The mean values for the three gas-mask factories varied from $\mathbf{3 1}$ for the Nottingham to 36 for the Blackburn, values which do not differ significantly. Prima facie there does not appear to be any correlation between latent period and fibre concentration. Nevertheless, as there is likely to be a distribution of latency for a given dose, the accumulation of more data may confirm the findings of Sheers and Coles $^{12}$ that, in the Devonport Dockyard workers, the time interval between first exposure and death from mesothelioma was least for those most heavily exposed.

\section{CHARACTERISTICS OF UNCOATED FIBRES}

The difference between the mean CMLs of uncoated fibres in the lungs of the Leyland and Nottingham gas-mask factory workers is not significant, and the similarities in distribution are shown in fig 3 . Roughly $30 \%$ of fibres occur in both the $5-10$ and in the 10-20 $\mu \mathrm{m}$ length categories. The deficiency of fibres under $5 \mu \mathrm{m}$ in length is due to their preferential macrophage-mediated clearance from the alveolar region. ${ }^{2} 8$ From the length distribution of uncoated fibres it is clear that those in the $5-10 \mu \mathrm{m}$ category are also cleared but less efficiently. Recent (unpublished) work on the clearance of sized glass fibres from the rat lung has confirmed that 5 and $10 \mu \mathrm{m}$ long fibres are cleared quite efficiently but that $30 \mu \mathrm{m}$ fibres are cleared very poorly, if at all. Timbrell ${ }^{4}$ has suggested that $17 \mu \mathrm{m}$ may be the effective upper limit for macrophage-mediated fibre clearance from the human lung. The fact that, although most are cleared, short fibres remain in the lungs of the gas-mask factory workers so many years after exposure shows that not all such fibres are removed, possibly due to their transfer to the pulmonary lymphatics or interstitium.

There does appear to be a relationship between fibre length and fibre concentration. Below concentrations of $10^{8} / \mathrm{g}$ dry weight, the proportion of 


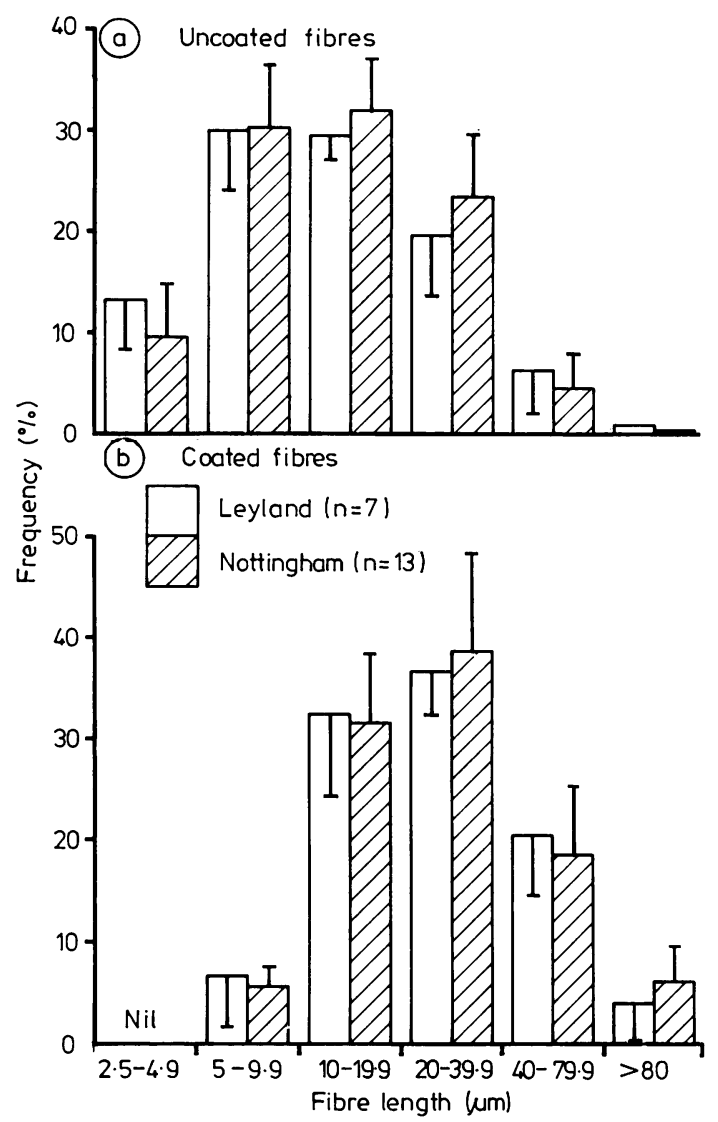

Fig 3 Mean length distributions of uncoated and coated fibres in Leyland and Nottingham gas-mask factory workers.

fibres less than $10 \mu \mathrm{m}$ in length is relatively constant at about $40 \%$. Once this concentration is exceeded, however, the proportion of short fibres starts to increase until at $10^{9} / \mathrm{g}$ dry weight it is over $90 \%$. As suggested previously ${ }^{2}$ this effect could be due either to the concentration of long fibres being so high as to impede the mobility of virtually all alveolar macrophages, to impairment of the clearance process by fibrosis, or to the transfer of a greater proportion of fibres to the lymphatic system. This means that at high fibre concentrations, the total fibre concentration in lung no longer provides an accurate index of integrated exposure. This effect can be avoided, however, if dose assessments are based on the number of long fibres present say, for example, those exceeding $20 \mu \mathrm{m}$ which are unaffected by macrophage-mediated clearance.

\section{CHARACTERISTICS OF COATED FIBRES}

The CMLs of coated fibres are, on average, about twice those of the uncoated. This is due to the fact that there is a greater probability of long fibres becoming coated than short.21314 Of the fibres remaining in the lung, few over $80 \mu \mathrm{m}$ in length are uncoated and few under $10 \mu \mathrm{m}$ are coated. As shown in fig 3, the mean length distributions of coated fibres in the Leyland and Nottingham workers were similar with maximun frequency occurring in the 20-40 $\mu$ m category.

The proportion of coated fibres varied from $1 \%$ to over $20 \%$; the mean value for both the Leyland and Nottingham factory workers was $11 \%$. The proportions of coated fibres in workers with high concentrations (A4, A6, and N5) are low because of the higher-than-normal population of short fibres that remain uncoated.There were cases with relatively low concentrations, however, where only a small proportion of fibres were coated. This suggests either that there are individual differences in the tendency of the lung to coat fibres of similar length and diameter or that the proportion of fibres that becomes coated varies from one region of the lung to another. In a recent (unpublished) study of the concentration of both uncoated and coated fibres taken from different regions of a sagittal slice of human lung it has been shown that the proportion of coated fibres increased from $3 \%$ at the pleural surface of the lower lobe to $44 \%$ close to the centre of the same lobe, a range which covers that observed in the present study. Possible reasons for the variation in the proportion of fibres that become coated will be discussed elsewhere.

In most of the subjects examined the coated fibres were relatively straight and the vast majority did not have "clubbed" ends. In cases with high fibre concentrations, however, the proportion of bodies that were distorted and that had clubbed ends increased. The distortion of asbestos bodies may result from the compression of tissue occurring during the development of fibrosis. Long fibres that had split longitudinally were invariably coated.

The cores of curved asbestos bodies have been studied recently by Churg et al ${ }^{15}$ who found that they all contained extremely thin amphibole fibres. It was suggested that such bodies are able to flex because of the "thinness" of the incorporated fibre. Arul and Holt $^{16}$ have suggested that asbestos bodies fragment into sections and that "when exposure to asbestos ceased many years before a mesothelioma developed, there may be few recognisable asbestos bodies remaining in the lung." Our observation of many long $(>80 \mu \mathrm{m})$ bodies in the lungs of the gas-mask factory workers 40 years after exposure, however, does not support this suggestion. 
We are indebted to Dr R H Cowdell, John Radcliffe Hospital, Oxford; Dr J S P Jones, City Hospital, Nottingham; Dr W G Owen, Royal Infirmary, Preston; Mr A Rogers, University of Sydney; and Dr F Whitwell, Broadgreen Hospital, Liverpool, who provided samples of lung tissue. Measurements with the electron microscope were made by $\mathrm{Mr} \mathrm{M} \mathrm{J}$ Heard and Mr R DWiffen of the Environmental and Medical Sciences Division, Harwell. We also acknowledge gratefully the support of the EEC Environmental Research Programme (Project 27777-10 ENV UK) and of the Asbestosis Research Council. Finally, we thank members of the ARC for constructive comments.

\section{References}

${ }^{1}$ Jones JSP, Pooley FD, Smith PG. Factory populations exposed to crocidolite asbestos-a continuing survey. INSERM Symposia Series Vol 52. IARC Scientific Publications No 13. INSERM, 1976;52:117-20.

2 Morgan A, Holmes A. Concentrations and dimensions of coated and uncoated asbestos fibres in the human lung. Br J Ind Med 1980;37:25-32.

${ }^{3}$ Friedrichs KH. Morphological aspects of fibers. In: Leman R, Dement JM, eds. Dusts and disease. Park Forest South, Illinois: Publishers Inc, 1979:51-61.

4 Timbrell V. Retention of fibres in human lung. In: Walton $\mathrm{WH}$, ed. Proceedings of 5th International Symposium on Inhaled Particles. Oxford, Pergamon Press.

${ }^{5}$ Jones JSP, Smith PG, Pooley FD, et al. The consequences of asbestos dust exposure in a wartime gas-mask factory. In: Wagner JC, ed. Proceedings of IARC Symposium in Biological Effects of Mineral Fibres. Vol 2. Lyon: IARC, 1979:637-53. (IARC Scientific Publication No 30.)

${ }^{6}$ Pooley FD. In: Glen HW, ed. Proceedings of Asbestos
Symposium, Johannesburg, 1977. Randburg, S Africa: National Institute of Metallurgy, 1978:31.

7 Timbrell V, Pooley F, Wagner JC. Characteristics of respirable asbestos fibres. In: Shapiro HA, ed. Pneumoconiosis. Proceedings of the International Conference, Johannesburg, 1969. Oxford: Oxford University Press, 1970:120-5.

${ }^{8}$ Holmes A, Morgan A. Clearance of anthophyllite fibres from the rat lung and the formation of asbestos bodies. Environ Res 1980;22:13-21.

9 McNulty JC. Asbestos exposure in Australia. In: Shapiro HA, ed. Pneumoconiosis. Proceedings of the International Conference, Johannesburg, 1969. Oxford: Oxford University Press, 1970:201-3.

${ }_{10}$ Whitwell F, Scott J, Grimshaw M. Relationship between occupations and asbestos fibre content of the lungs in patients with pleural mesothelioma, lung cancer, and other diseases. Thorax 1977;32:377-86.

${ }^{11}$ Hobbs MST, Woodward S, Armstrong BK, Must AW. Monitoring of cancer risk in previous crocidolite miners in Western Australia. Proceedings of IARC Symposium on Biological Effects of Mineral Fibres. Lyon: IA RC (in press).

${ }^{12}$ Sheers G, Coles RM. Mesothelioma risks in a Naval Dockyard. Arch Environ Health 1980;35:276-82.

${ }^{13}$ Morgan A. Effect of length on the clearance of fibres from the lung and on body formation. In: Wagner JC, ed. Proceedings of IARC Symposium on Biological Effects of Mineral Fibres. Vol 1. Lyon: IARC, 1979:329-35. (IARC Publication No 30.)

11 Ophus EM, Mowe G, Osen KK, Gylseth B. Scanning electron microscopy and $\mathrm{x}$-ray microanalysis of mineral deposits in lungs of a patient with pleural mesothelioma. Br J Ind Med 1980;37:375-81.

${ }^{15}$ Churg A, Warnock ML, Green N. Analysis of the cores of ferruginous (asbestos) bodies from the general population. II True asbestos bodies and pseudo asbestos bodies. Lab Invest 1979;40:31-8.

${ }^{16}$ Arul KJ, Holt PF. Clearance of asbestos bodies from the lung: a personal view. Br J Ind Med 1980;37:273-7. 